\title{
A Study of Coronary Artery Predominance and Its Clinical Importance
}

\author{
${ }^{1}$ Puli Darmender, ${ }^{2}$ Seema Madan, ${ }^{3}$ Takkallapalli Anitha \\ ${ }^{1,3}$ Department of anatomy, Chalmeda Anandarao Institute of Medical Sciences, Karimnagar, Telangana, India \\ ${ }^{2}$ Department of anatomy, Gandhi Medical college, Secunderabad, Telangana, India
}

\begin{abstract}
With the increasing trends of coronary heart diseases, the knowledge of variations in the coronary arteries is of paramount importance when considering the various surgical procedures. This study was conducted to know the variations in coronary artery dominance pattern. 77 formalin fixed hearts were dissected. Origin and area of distribution of posterior interventricular artery and SA nodal artery were noted. In 64 hearts (83.11\%) posterior inter ventricular artery was a branch of right coronary artery and in 13 hearts (16.88\%) it was a branch of left circumflex artery. SA nodal artery was a branch of dominant artery in 46 hearts (59.74\%). It arose from non-dominant artery in 29 hearts (37.66\%). In the remaining 2 hearts (2.6\%) SA nodal artery was a branch from both.
\end{abstract}

Key words: Right coronary artery, Posterior interventricular artery, SA nodal artery, Coronary dominance.

\section{Introduction}

The prevalence of coronary heart diseases in India is increasing rapidly, it was 1\% in 1960 and $9.7 \%$ in $1995^{1}$. Now in India coronary heart disease has become one of the leading cause of death in middle class population. This study was conducted to help the physicians and surgeons to understand the pattern of coronary artery dominance while performing therapeutic and surgical procedures. In 1940 Schlesinger ${ }^{2}$ developed the concept of balanced (or) predominance in coronary artery circulation on the diaphragmatic surface of heart. According to Blunk and DiDio ${ }^{3}$ all cases in which right coronary artery provides posterior interventricular artery is considered as right coronary dominance.Coronary dominance is characterized by presence of a coronary branch irrigating SA node which could be originated from either right (or) left coronary artery (Grey and Mayo $1988)^{4}$.

\section{Materials And Methods}

77 hearts preserved in 10\% formalin were collected from Department of Anatomy, Chalmeda Anandarao Institute of Medical Sciences, Karimnagar. Visceral pericardium was removed and coronary arteries were exposed. Origin, course and area of distribution of posterior interventricular artery and SA nodal artery were noted.

The following parameters were chosen for present study:

1. Origin of posterior inter ventricular artery to determine the coronary artery dominance.

2. Origin of SA nodal artery to correlate with coronary dominance.

All our observations were meticulously analyzed, tabulated and compared with earlier studies.

\section{Results}

Table no: 1 Origin of posterior interventricular artery

\begin{tabular}{|l|l|l|l|l|}
\hline Name of the artery & \multicolumn{3}{|l|}{ From right coronary artery } & From left circumflex artery \\
\hline $\begin{array}{l}\text { Posterior interventricular } \\
\text { artery }\end{array}$ & Total no. & Percentage & Total no. & Percentage \\
\cline { 2 - 5 } & 64 & $83.11 \%$ & 13 & $16.88 \%$ \\
\hline
\end{tabular}

Table no: 2 Origin of SA nodal artery

\begin{tabular}{|l|c|c|c|c|c|c|}
\hline Name of the artery & \multicolumn{2}{|c|}{ From dominant artery } & \multicolumn{2}{c|}{ From nondominant artery } & \multicolumn{2}{c|}{ From both } \\
\hline \multirow{2}{*}{ S A nodal artery } & Total no. & Percentage & Total no. & Percentage & Total no. & Percentage \\
\cline { 2 - 7 } & 46 & $59.74 \%$ & 29 & $37.66 \%$ & 2 & $2.6 \%$ \\
\hline
\end{tabular}

\section{Discussion}

Anatomical knowledge of variations in branching pattern of coronary arteries is important because in all coronary artery bypass grafting surgeries choice of therapy depends on the origin, number, location, area of distribution of coronary arteries.

The coronary artery which gives a posterior interventricular branch at crux cordis is considered as dominant artery. Coronary dominance can be right or left. When both right and left coronary arteries provide the 
posterior interventricular artery, it is considered as balanced pattern. Irrespective of coronary dominance, left coronary artery supplies the larger area of ventricular myocardium ${ }^{5,6}$. Left coronary dominance is clinically important since it irrigates larger area and associated with higher incidence of arteriosclerosis and acute infarction $^{7}$.

As the right coronary artery approaches the crux it produces one to three branches, among these only one posterior interventricular (descending) branch travels in posterior interventricular grove ${ }^{9}$. Cavalcanti JS $^{10}$ observed during his study on 110 cardiac specimens that the posterior interventricular artery is seen to arise from right coronary artery in $88.18 \%$ of hearts and from left circumflex artery in remaining $11.82 \%$. Results of Christos E nerantzis ${ }^{11}$ work on 60 hearts were also similar. According to him posterior interventricular artery is a branch of left circumflex artery in $12 \%$ and in $88 \%$ of hearts posterior interventricular artery arose from right coronary artery. In our present study posterior interventricular artery arose from left circumflex artery in 13 hearts $(16.88 \%)$ and in 64 hearts $(83.11 \%)$ it was a branch of right coronary artery[table no: 1\&3][figure: 1]. A clear right coronary dominance is observed in present study and no balanced pattern of coronary dominance was observed.

Coronary artery dominance plays important role in inferior wall infarcts. Though these are less extensive than anterior wall infarcts these can be dangerous because they can cause various degrees of atrioventricular block in $30 \%$ of cases. In right coronary dominant pattern right coronary artery also supplies the atrioventricular node. Occlusion of right coronary artery will have higher risk of atrioventricular block ${ }^{8}$.

Table no: 3 origin of posterior interventricular artery compared with earlier studies

\begin{tabular}{|l|l|l|l|}
\hline Origin & Cavalcanti JS & Christos E.Nerantzis & Pesent study \\
\hline From right coronary artery & $88.18 \%$ & $88 \%$ & $83.11 \%$ \\
\hline From circumflex artery & $11.82 \%$ & $12 \%$ & $16.88 \%$ \\
\hline
\end{tabular}

Artery to SA node is an atrial branch which supplies the myocardium of both atria, mainly the right. Its origin is 'variable; it comes from the circumflex branch of left coronary artery in 35\%. However, more commonly it arises from the anterior atrial branch of right coronary artery?

The study of Ramanathan $\mathrm{L}^{13}$ showed that the SA nodal artery is a branch of dominant artery in $36 \%$ of cases, in contrast to this in our present study it was a branch of dominant artery in $59.74 \%$ (46 hearts), in $37.66 \%$ (29 hearts) it arose from non dominant artery[figure: 2]. And in remaining 2.6\% (2 hearts) SA nodal artery arose from both right coronary and left circumflex arteries[table no: 2]. From above observations it is clear that in majority of cases SA nodal artery is a branch of dominant artery. Right coronary artery is dominant artery which provides posterior interventricular artery and SA nodal artery.

SA nodal artery is anatomically significant since it is used as landmark to identify SA node. Risk of intra operative damage to the SA nodal artery is high during superior transseptal approach to the mitral valve because it crosses the posterosuperior border of the inter atrial septum in $54 \%$ of cases ${ }^{12}$.

Developmentally there is a dual origin of coronary arteries, proximal and distal. The distal portion develops first. It is comprised of a retiform vascular network, similar to the capillary network that forms in the other parts of body. This network develops in the interventricular and atrioventricular grooves and forms a complete ring around the developing vessels (peritruncal ring) and communicates with the heart chamber and extra cardiac great vessels. Further development of some vessels and regression of others, the final coronary pattern develops. This theory adequately explains the variations of coronary vasculature ${ }^{14,15}$.

\section{Conclusion}

Irrespective of criteria taken in to account right coronary dominance is the common pattern. Right coronary artery supplies to major area of diaphragmatic surface of the heart through posterior interventricular artery and also provides a branch to SA node in majority of cases. These points are also to be considered while deciding the choice of therapy in right coronary artery occlusion.

\section{Acknowledgements}

The authors are grateful to the management of chalmeda anandarao institute of medical sciences and to Dr Supriya Raj for suggesting this journal for publication.

\section{References}

[1]. Mandal S, Saha JB, Mandal SC, Bhattacharya RN, Chakraborty M, Pal PP. Prevalence of ischemic heart disease among urban population of Siliguri, West Bengal. Indian J Community Med. 2009; 34: 19-23.

[2]. Schlesinger, MJ. Relation of the anatomic pattern to pathologic conditions of the coronary arteries. Arch Path 1940; $30: 403-15$.

[3]. Blunk, JN, DiDio, LJA. Types of coronary circulation in human hearts. Ohio State Med J 1971; 67: $596-607$.

[4]. Gray, H. \& Mayo, C. Gray: Anatomia . Sao Paulo, Guanabara Koogan, 1988. 
[5]. Kato T, Yasue T, Shojy Y, Shimabukuro S, Ito Y, Goto S, et al. Angiographic difference in man, dog, pig and monkey. ActaPatholJpn. 1987; 37(3):361-73.

[6]. Falci Jr. R, Guimaraes MH, Santos APS, Cabral RH, Jatene FB, Prates NEVB. Estudocomparatio do padrao de circulacaocoronariana entre pecasanatomicas e pacientescirurgicos. Rev HospClinFac Med Univ Sao Paulo. 1996;51(6):224-7.

[7]. Goldberg A, Southern D, Galbraith P.D, Traboulsi M, Knudtson M.L, Ghali W A. Coronary dominance and prognosis of patients with acute coronary syndrome. Am. Heart J.2007 Dec; 154(6): 1116-1122.

[8]. Amin K, Javed M, Mehmood A, Zakria M. Acute Inferior Wall Myocardial Infarction: Frequency of AV Blocks. The Professional. 2004 Jan, Feb, Mar; 11(1): 31-37.

[9]. Susan Standring, Harold Ellis. Gray's Anatomy. 39th Ed. 2005; Pg: 1014-1018.

[10]. Cavalcanti JS, de Lucena Oliveira M, Pais e Melo AV Jr, Balaban G, de Andrade Oliveira CL, de Lucena Oliveira E; Anatomic variations of the coronary arteries. Arq Bras Cardiol. 1995Dec; 65(6):489-92.

[11]. Christos E. Nerantzis, Christos A. Lefkidis, Tatiana B. Smirnoff, Emmanouil B. Agapitos, panagiotis S. Davaris; Variations in the origin and course of the posterior interventricular artery in relation to the crux cordis and the posterior interventricular vein: An anatomical study. The Anatomical Record Part A: Discoveries in Molecular, Cellular, and Evolutionary Biology, Dec 1998; 252 (3):413-417.

[12]. Berdajs D, Patonay L, Turina MI. The clinical anatomy of the sinus node artery. Ann Thorac Surg. 2003; $76: 732-5$.

[13]. Ramanathan L, Shetty P, Nayak SR, Krishnamurthy A, Chettiar GK, Chockalingam A.; Origin of the sinoatrial and atrioventricular nodal arteries in South Indians: an angiographic study. Arq Bras Cardiol.2009 May; 92(5): 314-9,330-5,342-8.

[14]. Decker, G.A.G, duplessis, DJ; LecMcgregor's synopsis of surgical anatomy, 12th edition, ch-22 "The heart and the great vessels",pg-280; K.M.varghese company, Dadar, Bombay 4000014, India, 1986.

[15]. Ogden J: The origin of the coronary arteries; circulation 1968[38]: Suppl 6:150.

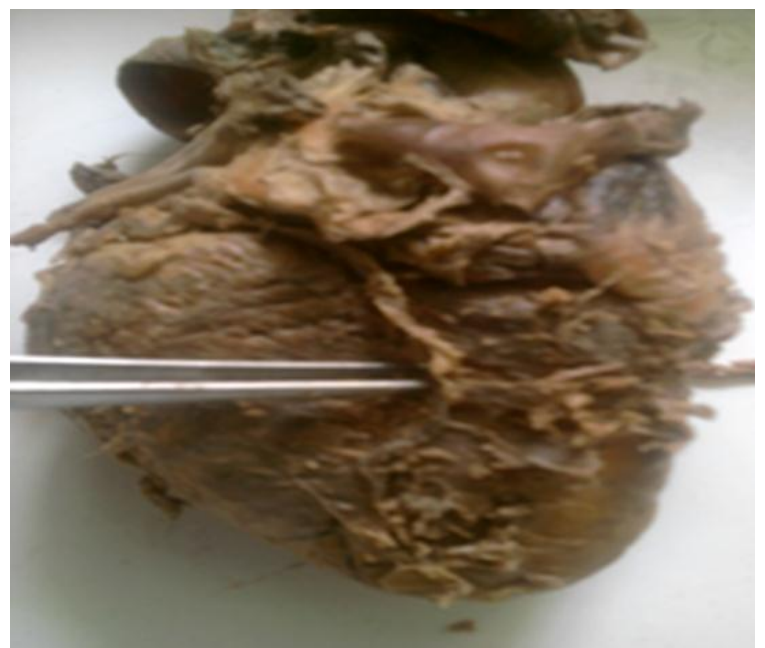

Figure 1: Origin of posterior interventricular artery from left circumflex artery

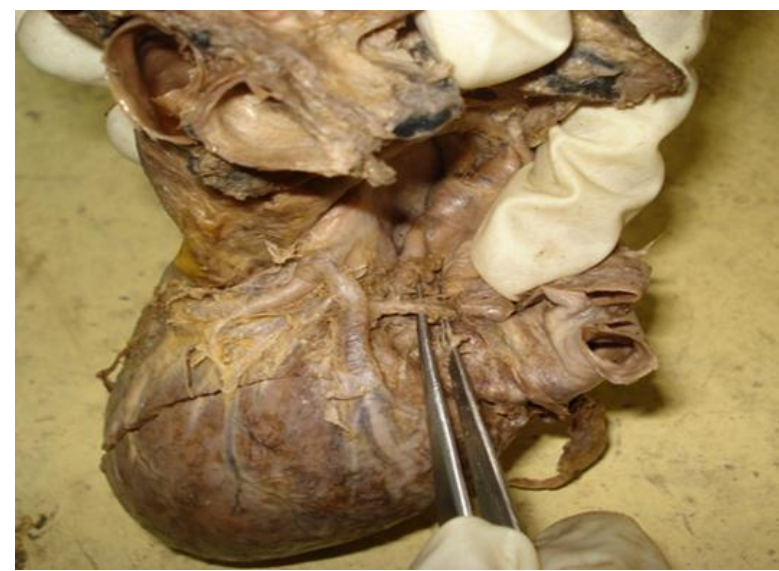

Figure 2: SA nodal artery arising from nondominantleft circumflex artery 